\title{
BORGES: NOSTALGIA E INVENCIÓN
}

\author{
Beatriz Sarlo \\ Escritora
}

Resumen: A treinta años de la muerte de Jorge Luis Borges, este ensayo explora la relación entre sus antepasados y la nostalgia del escritor argentino por un mundo perdido, donde la acción, el coraje y el heroísmo todavía eran posibles. De acuerdo con la autora, Borges sabe que la modernidad extinguió ese mundo para siempre, pero sabe también que él tiene la oportunidad de invocarlo y hacerlo, a través de la literatura, "más duradero que el bronce".

Palabras Clave: Borges, América, batallas de Independencia, Martín Fierro, gauchismo, fundación de la modernidad.

\section{BORGES: NOSTALGIA AND INVENTION}

ABSTRACT: Thirty years after the death of Jorge Luis Borges, this essay explores the relationship between his predecessors and the Argentine writer's nostalgia for a lost world where action, courage and heroism were still possible. In the author's opinion, Borges knew that modernity made that world forever extinct, yet also that he had the chance, through literature, to invoke it and make it "more lasting than bronze."

Keywords: Borges, America, the battles for Independence, Martin Fierro, gauchismo, the foundation of modernity.

Beatriz SARLo. Ensayista y escritora argentina. Ha sido fellow del Wilson Center (Washington), Simón Bolívar Professor of Latin American Studies en la Universidad de Cambridge y becaria del Wissenschaftskolleg, Berlín. Autora del ya clásico Borges, un escritor en las orillas (1993). Algunos de sus últimos libros son Ficciones argentinas (Buenos Aires: Mardulce, 2012); Viajes: De la Amazonia a Malvinas (Buenos Aires: Seix Barral, 2014) y Zona Saer (Santiago: UDP, 2016). Email: beatriz. sarlo@gmail.com. 


\section{EL VACÍO DEL PRESENTE Y LA VERDAD DE LA HISTORIA}

B orges tiene una versión en caída de la historia nacional. Sus héroes pertenecen casi sin excepción al pasado, porque la Edad Heroica, como corresponde a toda versión decadentista, ha quedado atrás. ¿Muy lejos? No tanto, porque la cercanía de esta lejanía, si se permite la contradicción, es un rasgo de la temporalidad americana. Los héroes de Occidente, como en "El inmortal", pueden ser el mismo Homero que padece la humillante degradación de su inmortalidad; los héroes americanos, en cambio, viven en la corta duración. Su presente transcurre en un tiempo "bajo" comparado con los escenarios donde la imaginación literaria dispone a sus héroes. Pero en los siglos que conducen de la Edad Heroica a la pérdida de aquellas virtudes pretéritas Borges interviene con la historia de "El inmortal", y el remoto Homero se bestializa; habita la ciudad con los trogloditas; es Flaminio Rufo; transcribe los viajes de Simbad; lee la Ilíada traducida por Pope; y luego, en el siglo XX, el anticuario Joseph Cartaphilus observa lo que fue ese Otro múltiple, sucesivo y pretérito desde la perspectiva de un hombre cuya vocación es el pasado, redimido, como afirmaría Benjamin, en la conservación de textos y manuscritos. Es la historia en su larga duración. ${ }^{1}$

Borges capturó también la temporalidad corta en algunos relatos de Historia universal de la infamia, donde los personajes de la cultura popular norteamericana, como Billy the Kid o Monk Eastman, muestran la degradación de lo heroico moderno. En este terreno "bajo" la literatura interviene siguiendo la crónica roja. Su primer libro de relatos explora las posibilidades literarias de esa materia popular, cuyos héroes son timadores o asesinos. ${ }^{2}$

${ }^{1}$ Sobre las sucesivas encarnaciones de "El inmortal", Carlos Gamerro observa: "Con el paso de los siglos y, en su caso, de los milenios, Homero terminó olvidándose de que era Homero y 'tomó prestada' una memoria falsa, más nueva, más reciente: la de su compañero de varios siglos Flaminio Rufo. Y como la identidad personal depende de la memoria, al apropiarse de los recuerdos de Flaminio Rufo, termina creyéndose Flaminio Rufo, siendo Flaminio Rufo" (Gamerro, Borges y los clásicos (Buenos Aires: Eterna Cadencia, 2016), 46).

${ }^{2}$ Historia universal de la infamia fue publicado en 1935. Algunos de los textos que incluye este libro aparecieron en 1933, en el muy popular diario Crítica. En el prólogo a la primera edición, Borges afirma que uno de los rasgos de esos relatos es "la reducción de la vida de un hombre a dos o tres escenas", indicación con que puede leerse el cuento que se analizará un poco más adelante, "Tema del traidor y del héroe". 
Trabajar en los márgenes: Borges funda el margen criollo entre la ciudad y la pampa, ese espacio incierto que llamó "las orillas", donde la verdad de su criollismo se define en la indecisión entre aquello que todavía no es del todo ciudad y aquello que todavía no es del todo extensión desierta: la "calle sin vereda de enfrente", las últimas casas cuyos cercos dan sobre la llanura. El tiempo de "las orillas" es un pasado reciente; sus héroes son sombras que Borges dice haber conocido o cuyas historias dice haber escuchado.

Las orillas, territorio de Fervor de Buenos Aires, Luna de enfrente y Cuaderno San Martín, los tres primeros libros de poemas, no existen en cualquier tiempo. Son un cronotopo, una unidad de espacio y tiempo que tiene su ethos, su paisaje y sus actores. Son un mito joven, casi recién inventado. A diferencia de otros grandes escritores, Borges conoce su Troya porque, como sostén referencial de ese lugar literario, las orillas de Buenos Aires se parecen mucho a las de la ciudad que dejó a los catorce años cuando viajó con su familia a Suiza. Se fue de la ciudad cuando ni siquiera la conocía del todo: el más fuerte impulso de la nostalgia es haberse alejado de aquello que apenas se tuvo a medias. Esta separación en la primera adolescencia y hasta la juventud, ya que Borges regresa a Buenos Aires en 1921, provoca la dimensión nostálgica que será una de las texturas de su obra:

Las calles de Buenos Aires

ya son la entraña de mi alma.

No las calles enérgicas

molestadas de prisas y ajetreos,

sino la dulce calle de arrabal

enternecida de árboles y ocaso

y aquellas más afuera

ajenas de piadosos arbolados

donde austeras casitas apenas se aventuran

hostilizadas por inmortales distancias

a entrometerse en la honda visión

hecha de gran llanura y mayor cielo. ${ }^{3}$

3 "Las calles", Fervor de Buenos Aires, primera edición 1923. Se cita de Poemas. 1922-1943 (Buenos Aires: Losada, 1943). 
Unidad de espacio y tiempo, las orillas son el modelo de un territorio mítico original, donde hubo gauchos, soldados, compadritos y orilleros (esa tipología cuyo nombre proviene del espacio que habitan). Casi con las mismas palabras, Borges define su programa:

Ante esa indecisión de la urbe donde las casas últimas asumen un carácter temerario como de pordioseros agresivos frente a la enormidad de la absoluta y socavada llanura, desfilan grandemente los ocasos como maravilladores barcos enhiestos (...). El desinterés estético de los arrabales porteños es patraña divulgadísima entre nosotros. Yo que he enderezado mis versos a contradecir esta especie... ${ }^{4}$

¿A la ciudad le faltan fantasmas? Borges, que se hizo esta pregunta y creyó percibir una ausencia, los buscó en el territorio literario original de las orillas. Este descubrimiento, fundación y autofundación imaginarias, perdura en el cronotopo mítico como base figurativa, retórica y cultural. Pero, a diferencia de los escritores europeos que se mueven a lo largo de los siglos, de Homero a Dante y Shakespeare, los argentinos tienen un pasado de corta duración: las orillas lo son de un tiempo y un espacio cercanos, casi familiares incluso para un hombre de ciudad, "un pueblero", que nació, como Borges, en 1899.

Por eso debió producir (¿inventar?) una familiaridad con el pasado. Disponía de las huellas que habían llegado hasta él: las de su historia familiar y las de una primera experiencia joven, reconocida y configurada por un imaginario que se constituye casi al mismo tiempo que se experimenta la ciudad y se la convierte en materia de la literatura (Borges reconoce en Evaristo Carriego, poeta discreto y barrial, una sensibilidad de su mismo género y le dedica un ensayo publicado como libro en 1930, es decir, cuando todavía no había terminado su primer período). Construye su subjetividad y su estética al mismo tiempo, de modo indiscernible una de la otra: percibe lo que quizá ya sabe que será su materia literaria. En los años veinte, el pasado criollo está definitivamente terminado para la literatura. Incluso Don Segundo Sombra, de Ricardo Güiraldes, a quien Borges aprecia, solo le despierta una ironía

${ }^{4}$ Inquisiciones, primera edición 1925. Se cita de Inquisiciones (Buenos Aires: Seix Barral, 1993), 89. 
benevolente y una consideración respetuosa pero desinteresada. Las supervivencias folclorizantes no tienen, para Borges, la densidad estética de la gauchesca que pudo fusionar la moral austera y el impulso sanguinario: un ethos que siempre lo fascinó y que, en sus ficciones, tiene carácter transhistórico o, dicho con más precisión, despliega distintos cronotopos de espacio y tiempo: la antigüedad mediterránea o la pampa del Martín Fierro.

Siempre me ha impresionado la ejemplaridad programática de un breve relato incluido en El hacedor. ${ }^{5}$ Su personaje es, entre todos los posibles, Homero, un fundador de mitos y él mismo un mito. Aquel mundo bárbaro, donde los dioses eran tan vengativos como los hombres, y tan caprichosos como sus mujeres, fue la materia de "un rumor de gloria y de hexámetros" en los dos poemas épicos que están en el inicio de la literatura occidental (seguramente, junto con la Biblia). En el relato de Borges, Homero, que ya ha terminado su gran obra, es un cuerpo envejecido sobre el que cae la noche de la ceguera. Antes ha iluminado con sus hexámetros la barbarie de ese puñado de islas y penínsulas en el Egeo. Homero es, en este final de vida, casi un salvaje, que desgarra la carne de jabalí con "dentelladas blancas y bruscas", como si los héroes y los hexámetros ya fueran materia del olvido y, al mismo tiempo, mostrando que ese desgarrar de fiera forma parte del mundo feroz donde esos poemas fueron cantados y de allí salieran, como dice Borges, todas las historias. El cuerpo envejecido de Homero recuerda sus impulsos, los más primitivos, y también recuerda una pelea a cuchillo (todos los duelos están en éste, que el argentino atribuye a Homero, como antecesor y como homenaje de las orillas).

Borges, en cambio, vive en un mundo caído y no puede recordar una experiencia a la altura de los mitos que funda: ésa es su pérdida y su nostalgia. Lo dice muchas veces, cuando se compara con sus antepasados, alguien que no tiene esos impulsos del cuerpo que retornan en el viejo Homero cuando clava sus dientes en la carne o recuerda un cuchillo ensangrentado, y que Borges describe, en "Historia del guerrero y la cautiva", como "un ímpetu secreto, un ímpetu más hondo que

${ }^{5}$ Es el primero del volumen, cuya primera edición es de 1960, y el que le da título: El hacedor. Citado de Obras completas (Buenos Aires: Emecé, 1974), en adelante sólo $O . C$. 
la razón". ${ }^{6}$ Los cautivos blancos que, después de vivir en las tolderías, vuelven transformados por la cultura a la que no pertenecían pero en la que se inscribieron, son la prueba que ofrece Borges a sus lectores de la fuerza primordial de un mundo arcaico, donde el ímpetu todavía no ha sido desplazado por la razón y donde el cuerpo, para usar una fórmula de Spinoza, es teatro de una lucha:

No han faltado, con todo, hombres muy eminentes (a cuya labor y celo confesamos deber mucho), que han escrito muchas cosas preclaras acerca de la recta conducta de vida, y han dado a los mortales consejos llenos de prudencia, pero nadie, que yo sepa, ha determinado la naturaleza y la fuerza de los afectos, ni lo que puede el alma, por su parte, para moderarlos. ${ }^{7}$

En estos relatos de Borges, la fuerza que modela estos impulsos es azarosa y de origen divino: la heroicidad. Por lo tanto, sobre el oscuro fondo primitivo, no está la razón vencedora, sino otra potencia desconocida, la del "alma", como la llama Spinoza, es decir, un ethos cuyos poderes y cuyos límites son tan misteriosos como los de la oscuridad del impulso. En este dilema se mueven los textos de Borges que es, al mismo tiempo, un escéptico porque sus ficciones muestran que hay inevitables caminos diferentes y actos en conflicto con las ideas y la razón, actos que suceden porque es imposible y quizá no sea sensato impedirlos. Borges no es un moralista. Explora todas las posibilidades y todos los caminos del impulso: la fascinación por la barbarie que sienten los cautivos de la toldería y el reflejo animal que vuelve en la dentellada del anciano Homero.

Desde un comienzo, en los cuentos de Historia universal de la infamia, hasta El hacedor, que es perfecto y tan original como aquel comienzo, Borges recorrió un territorio que, al mismo tiempo, iba inventando. Usó fragmentos de la tradición gauchesca, sobre todo del Martín Fierro, pero también ecos de los "cielitos" y "estilos" de la poesía popular octosilábica, ese metro familiar a la entonación del castellano. Llevó a ese territorio todas las ficciones populares y cultas: del policial hasta la violencia del infierno de la Divina comedia.

\footnotetext{
6 "Historia del guerrero y la cautiva", El Aleph, en O.C., 557-60.

${ }^{7}$ Spinoza, Ética, vol. III, "Prefacio" (Madrid: Alianza, 2009), 191-192.
} 
A Borges lo caracterizó de manera original la mezcla de motivos y estilos de diferentes niveles culturales, sin plebeyismo ni populismo, como si atravesara incólume los afluentes de culturas escritas y orales de las que tomaba inflexiones, absteniéndose de proponer su "salvación" literaria. El milagro borgeano, hecho posible por la radicalidad de su ironía, es recorrer estos caminos sin parecerse a ninguno de los escritores que los recorrieron con la ilusión de hacer una "apropiación culta". ${ }^{8}$ Borges se mueve en ese territorio con la naturalidad de alguien que pertenece a esa región. Y, sin embargo, él la está creando en sus ficciones, porque la mezcla de afluentes literarios cultos y populares es su verdadera invención estética.

Sabe que el gran poeta de la gauchesca, José Hernández, es irrepetible. Frente a ello se abren varias posibilidades: convertirlo en el antecesor cuya grandeza inmoviliza a quienes vienen después; venerarlo como escritura fatalmente definitiva y, por lo tanto, seguirla como se sigue un ritual; o hacer de la poesía gauchesca un territorio que se incorpore a otro más vasto, que Borges recorre (no siempre, no constantemente, pero sí en los momentos significativos), y contradecirla. En 1926 imagina un nuevo José Hernández que fuera capaz de redimir al arrabal del pintoresquismo costumbrista:

Sólo hay un camino de eternidad para el arrabalero (...). La receta es demasiado sencilla. Basta que otro don José Hernández nos escriba la epopeya del compadraje y plasme la diversidad de sus individuos en uno solo (...). Cualquier paisano es un pedazo de Martín Fierro; cualquier compadre ya es un jirón posible del arquetípico personaje de esa novela. ${ }^{9}$

Por eso, es preciso fundar de nuevo lo que parece insuperable o, como dice Harold Bloom, luchar con el poeta fuerte. Por eso, el Martín Fierro es otro, diferente, después de Borges. Quizá su mayor homenaje a José Hernández haya sido la bella paráfrasis del duelo de Martín Fierro con un moreno en un baile. Éste es el original:

${ }^{8}$ Por ejemplo, Ricardo Güiraldes con Don Segundo Sombra, novela publicada en 1926.

9 "Invectiva contra el arrabalero", El tamaño de mi esperanza, primera edición 1926. Se cita de edición de 1993 (Buenos Aires: Seix-Barral), 125. 
Por fin en una topada

en el cuchillo lo alcé-

y como un saco de güesos

contra un cerco lo largué.

Tiró unas cuantas patadas

y ya cantó pa el carnero-

nunca me pude olvidar

de la agonía de aquel negro.

Limpié el facón en los pastos,

desaté mi redomón-

monté despacio, y salí

al tranco pa el cañadón. ${ }^{10}$

Borges reescribe esta escena clásica. Su paráfrasis cumple la misma función que las citas de Homero en Virgilio o de Virgilio en Dante: columnas que sostienen una literatura en el tiempo. La reescritura borgeana no sólo es singularmente diestra, sino que además la contrapone a los fuegos retóricos de Leopoldo Lugones, quien, a comienzos del siglo $\mathrm{XX}$, aspiraba ser el nuevo portador de la corona de poeta nacional. Así Borges sigue y compite, al mismo tiempo, con Lugones y Hernández: "Alza a un moreno con el cuchillo, lo tira como un saco de huesos, lo ve agonizar y morir, se agacha para limpiar el acero, desata su caballo y monta despacio para que no piensen que huye". ${ }^{11}$ Un ethos bárbaro que reivindica sus virtudes y sus cualidades imposibles en el siglo XX.

\section{HISTORIA PERSONAL}

Cabe aquí una hipótesis biográfica, de esas que fueron desacreditadas en los años estructuralistas de la muerte del "sujeto". Borges pertenece de manera real a la élite rioplatense que vivió en el mundo de fronteras, de indios y de gauchos en el siglo XIX, después de regresar de las guerras de la independencia suramericana: "la sombra militar de mis

${ }^{10}$ José Hernández, El gaucho Martín Fierro, canto VII.

${ }^{11}$ Borges, "Martín Fierro", El hacedor, en O.C., 797. 
muertos". ${ }^{12}$ Sus abuelos fueron soldados tanto en esas guerras como en la frontera con las naciones indias. ${ }^{13}$ Tiene la seguridad de un linaje, aunque formado por personajes más bien secundarios de la historia (con una excepción, que se verá, en la batalla de Junín). Su subjetividad más remota, la de infancia, ha sido marcada por los relatos escuchados en su casa, contados por su madre y su abuela Leonor Suárez Haedo, historias que luego podía corroborar en libros juzgados, en ese momento, definitivos.

Constituido en este medio, a los catorce años Borges experimenta el primer alejamiento europeo, distante de todo, salvo de esas historias que siguió escuchando. Justamente esa distancia también es una condición de la élite a la que pertenecía. Como Victoria Ocampo y su hermana Silvina, Borges conoció Europa sin que se interrumpiera el flujo de las memorias familiares sobre su origen nacional. Sólo en esto se parecen, pero este rasgo no es menor. Se trata de una educación relativamente cosmopolita, sobre el suelo seguro de la pertenencia a una patria (el abuelo de las Ocampo, recuerda Victoria en su autobiografía, había sido amigo de Sarmiento). Que la riqueza de los Ocampo y los Borges fueran inconmensurables, ya que las hermanas provenían de un sector enormemente poderoso de latifundistas bonaerenses, no quiere decir que ambas familias no hayan sido significativamente similares. Los Ocampo (como los Bioy y los Casares) se movían en el corazón de la oligarquía; los Borges eran una familia con recursos moderados para su clase. Pero unos y otros podían reconocerse en una densa trama histórica.

El linaje familiar de Borges le asegura un pasado, no un futuro. Podría decirse: Borges está destinado a un tiempo que ya no existe, a diferencia de Roberto Arlt, de origen inmigratorio, un recién llegado, que necesita e inventa una utopía anárquica y crítica. ${ }^{14}$ La subjetividad borgeana sólo puede ser escéptica: algo se ha perdido, se han roto las

12 "El amenazado", El oro de los tigres, en O.C., 1107.

${ }^{13}$ Véase el detallado estudio de Rosendo Fraga, Borges y el culto de los mayores, prólogo de María Kodama (Buenos Aires: Fundación Internacional Jorge Luis Borges, 2001).

${ }^{14}$ Véase especialmente en Los siete locos los sueños tecnológicos, anárquicos y futuristas que a Arlt le fascinaron. Sobre el tema: Beatriz Sarlo, La imaginación técnica. Sueños modernos de la cultura argentina (Buenos Aires: Nueva Visión, 1994). 
continuidades que parecieron naturales, propias de una especie de argentinos fundadores. Ignora las destrezas que cultivaron sus mayores, no es hombre de campo ni soldado pero "como tanto argentino, soy nieto y hasta bisnieto de estancieros"15. Tiene que resignarse a ser escritor. Ese destino contiene su irónica contraposición: afortunadamente fue escritor porque la historia ya no necesitaba de sus mayores, ni él podía seguir sus pasos. Es casi inevitable una visión del presente como reflujo y caída.

La subjetividad es melancólica y esa melancolía encierra la evocación y el sentimiento de que no es posible defender en el presente el legado por el que otros arriesgaron su suerte:

No haber caído
como otros mi sangre,
en la batalla.
Ser en la vana noche
el que cuenta las sílabas. ${ }^{16}$

Queda entonces la literatura: un reemplazo, un simulacro finalmente. Pero Borges, para quien la hipálage es una figura esencial del discurso y por eso es vana la tarea de quien cuenta las sílabas en la noche, acepta la literatura como la única pasión en un mundo sin batallas ni grandes heroísmos. Necesidad e imposibilidad del mito, en un presente donde se han perdido los vínculos reales y son indispensables las construcciones imaginarias.

La modernidad es un tiempo sin aventuras ni asombro, hostil a los instintos "nobles" como el coraje, que se degrada irremediablemente en el desafío de orilleros dispuestos a morir por bravuconada. En épocas pretéritas, la ausencia de instituciones civiles y políticas que remediaran las injusticias ejercidas por unos sobre otros volvió socialmente indispensable la unión de honor y coraje, porque un hombre solo podía vengar una afrenta por medio de sus actos. $\mathrm{O}$, por lo menos, tal es como una sociología histórica podría interpretar lo que, en la gauchesca y otras narraciones nacionales, se presenta como virtudes de la pasión, quizá desmesuradas e injustas, pero siempre movidas por una legitimi-

15 "La pampa y el suburbio son dioses", El tamaño de mi esperanza, 23.

16 “Tankas", O.C., 1089. 
dad que, como lo vio Nietzsche, se entrelaza de modo trágico con un impulso atávico y cruel.

Esas virtudes pasionales se desvanecieron cuando el ideal abstracto de las instituciones reemplazó a la ética concreta. Entre el tiempo de aquellos soldados y estancieros y el de los hombres de ciudad se ha corroído un vínculo físico, vitalista, experiencial con el mundo. Lector de Schopenhauer, Borges cree que hay un secreto conflictivo más allá de cualquier Representación y que la Voluntad pasional, que admira en sus antepasados, no siempre se lleva mal con el Intelecto.

\section{BATALLAS}

Borges escuchó el relato en su casa, rememorado por las mujeres de su familia. Es segura la hipótesis de que su madre, Leonor Acevedo, le haya contado la historia de su bisabuelo, Isidoro Suárez Laprida, vencedor en la batalla de Junín, que figura en el tercer tomo de la Historia de San Martín de Bartolomé Mitre, cuyo primer tomo apareció en Buenos Aires, en la Imprenta de La Nación, en 1887 (y el tercero, al año siguiente).

El coronel Francisco Borges, padre de Jorge Guillermo Borges, murió en 1874, de modo que la educación de quien, a su vez, educaría a Jorge Luis Borges tuvo la marca de su madre inglesa, Fanny Aslam. Pero es dable suponer que la Historia de Mitre estuviera en la biblioteca, aunque la familia mantuviera una resentida distancia frente a Mitre, que fue derrotado en La Verde, batalla en la que, una vez que Mitre había capitulado, se sacrificó Francisco Borges en un ataque final, suicida, una carga solitaria y desesperada. ${ }^{17}$ En "La Recoleta", que aparece casi al fin de su vida en Atlas, Borges usa el sustantivo "capitulación" refiriéndose al desenlace de la batalla de La Verde. Es bien evidente que el sustantivo ofrece una connotación moral negativa sobre Mitre.

Es posible suponer que el recuerdo del coronel Borges, muerto, en 1874, en La Verde, no fuera extirpado por las maravillosas historias que leyó o le contaron a su nieto cuando era un niño, en la famosa bibliote-

${ }^{17}$ Sobre estos últimos conflictos de la organización nacional argentina y, en especial, sobre Buenos Aires, véase: Natalio Botana, "La lucha por la capital", en Buenos Aires; historia de cuatro siglos, eds. José Luis Romero y Luis Alberto Romero (Buenos Aires: Editorial Abril, 1983), vol. 1, 313-324. 
ca de libros ingleses. Pero también es posible imaginar que Leonor Acevedo no olvidaría el relato de otra hazaña próxima, tan en el corazón de su familia. ¿Qué comunican esas páginas del tercer tomo de la obra de Mitre que mencioné al principio? Una batalla decisiva, la de Junín, donde el ejército libertador venció a los españoles por la valentía y la inteligencia de otro coronel, también antepasado de Borges, su bisabuelo materno, Isidoro Suárez.

La escena histórica tiene la densidad de lo fundacional. Poco después, en Ayacucho, Bolívar termina la tarea emancipadora. Ayacucho es el fin del dominio español en América del Sur. La decisión y el arrojo de un antepasado de Borges fueron decisivos en la batalla de Junín, que antecedió esa victoria final. A las cinco de la tarde, la batalla parecía perdida para el ejército de Bolívar, cuando dos escuadrones de la caballería colombiana fueron arrollados por los españoles. Pero el bisabuelo de Borges, al frente del escuadrón de caballería del Perú, dejó "pasar el tropel de perseguidores y, despejado el terreno, cargó por la retaguardia a los vencedores que se pusieron en precipitada fuga". El comandante español informó más tarde: "Parecía imposible en lo humano que una caballería como la nuestra, tan bien armada, montada e instruida, con tanta vergüenza huyese de un enemigo sumamente inferior bajo todos los aspectos". Eso que parecía imposible, y que, según Mitre, aseguró no sólo el resultado en Junín sino el triunfo definitivo en Ayacucho, lo hizo el coronel Isidoro Suárez. Desde entonces, por decisión de Bolívar, el escuadrón comandado por el antepasado de Borges fue designado Húsares de Junín. ${ }^{18}$

Estas páginas de Mitre fueron leídas por el padre de Borges, ya que es poco probable que las desconociera. No sabemos si Borges las leyó en la misma primera edición que está hoy abierta sobre mi mesa: una edición que perteneció a mi padre, hombre nacido en 1899, como Borges, y que cursó el bachillerato en el mismo Colegio Nacional Manuel Belgrano donde Borges fue alumno en primer año. De todos modos, no es arriesgada cualquier inferencia sobre el respeto de Borges por su bisabuelo, el coronel de los Húsares de Junín. Los Borges eran coleccionistas de memorias familiares, independientemente de la casi inevitable Historia de Mitre. Por grande que fuera la influencia de su abuela pater-

${ }^{18}$ Bartolomé Mitre, Historia de San Martín y de la emancipación sudamericana, tomo 3 (Buenos Aires: Imprenta de "La Nación", 1888). 
na inglesa, Borges aprendió tempranamente su genealogía de "nobleza patriótica". Allí estaba su madre, Leonor Acevedo, y también su abuela materna, la hija del coronel Suárez, el héroe de Junín, que acompañó a la familia a Europa, es decir, que estuvo próxima a Borges hasta que él llegó a la adolescencia. ${ }^{19}$

No sabemos si las mujeres leían la historia militar y política de Mitre sobre la emancipación de Sudamérica. Sí sabemos que se sentían portadoras de una historia patriótica que incorporaba sus apellidos. Mitre informa que Olavarría, compañero de armas del coronel Suárez, fue quien relató los pormenores de la carga de caballería en la batalla de Junín. Y que lo hizo en presencia de ese abuelo de Leonor Acevedo. ${ }^{20}$ Todo permite imaginar que la victoriosa decisión de Suárez estuvo entre los relatos que Borges escuchó muy temprano. Tan temprano que en Fervor de Buenos Aires, su primer libro, incluyó "Inscripción sepulcral", sobre el coronel Suárez y a él dedicado:

Dilató su valor sobre los Andes.

Contrastó montañas y ejércitos.

La audacia fue costumbre de su espada.

Impuso en Junín término venturoso a la lucha

y a las lanzas de Perú dio sangre española.

Escribió su censo de hazañas

en prosa rígida como los clarines belísonos.

Murió cercado de un destierro implacable.

Hoy es orilla de tanta gloria el olvido. ${ }^{21}$

Por su linaje Borges tiene ese lugar en el pasado. Y luego él mismo lo construyó, como quien hubiera recibido el legado familiar y supiera que su deber era convertirlo en literatura, única arma contra el olvido. Él tampoco pudo olvidarlo y son más los poemas que nombran al vencedor de Junín.

${ }^{19}$ Rosendo Fraga hipotetiza, con mucha verosimilitud, que esta abuela, Leonor Suárez Haedo, fue una trasmisora de historias. Véase Fraga, Borges y el culto, 29-33.

${ }^{20}$ Mitre escribe: "Estos detalles, que son de notoriedad histórica, han sido referidos por el coronel Olavarría, actor en la batalla, en presencia del coronel Suárez, que fue el héroe de ella" (Historia de San Martín, 728, n. 29).

21 “Inscripción sepulcral", Fervor de Buenos Aires, en Poemas, 30. 


\section{EL TEMA DE LOS HÉROES}

Como sea, en Borges todo se complica. Los héroes familiares tienen asegurado un modesto parnaso criollo; sin embargo, la construcción de un personaje heroico eventualmente puede resultar de estrategias que cumplen una función pública, aunque sostenidas por manipulaciones secretas de los sucesos que se le atribuyen como demostración de heroicidad. Borges no duda de las historias familiares, pero pone en cuestión otras historias, que no conciernen a su linaje, sino que afectan en profundidad las creencias acerca del modo en que el relato del pasado puede ser alterado incluso mientras transcurren los acontecimientos.

Esto pensaba al leer nuevamente "Tema del traidor y del héroe". Este cuento (o proyecto de cuento) Borges lo presenta como un "argumento" que quizás escriba en un futuro. El "argumento", hasta donde Borges lo "vislumbra" el 3 de enero de 1944, es todo lo que conocemos sus lectores. Fergus Kilpatrick fue un jefe de conspiradores en Irlanda, asesinado, según se creyó, por agentes británicos. Su bisnieto, Ryan, quiere escribir un libro sobre Kilpatrick. ${ }^{22}$ Sabe que su antepasado fue muerto poco antes de una insurrección nacionalista victoriosa, pero los detalles y responsables del crimen permanecieron en las sombras durante más de cien años.

A Ryan no lo satisface la solución que han adoptado los historiadores: es decir, que el asesinato fue un crimen más de los británicos. Le sorprenden algunos paralelismos con los avisos que Julio César recibe antes de su asesinato, y una cita de Shakespeare que podría llegar de las brujas de Macbeth. Ryan descubre, por así decirlo, que James Alexander Nolan, camarada de Kilpatrick, había traducido en 1814 varias obras de Shakespeare al gaélico.

En 1824, se reúnen los conjurados nacionalistas. Pero, como ya había sucedido otras veces, hay un traidor. Nolan revela que el traidor es el propio jefe Kilpatrick y se decide ejecutarlo. Pero exponerlo públicamente como traidor mancharía no sólo su nombre, sino la devoción

22 Daniel Balderston indica que Ryan es bisnieto de Kilpatrick y Borges, bisnieto de Isidoro Suárez. Véase Balderston, "Digamos Irlanda, digamos 1824”, en Innumerables relaciones. Cómo leer con Borges (Santa Fe: Universidad Nacional del Litoral, 2010), 106. 
que el pueblo siente por él y la insurrección misma. El plan es convertir al traidor en héroe y matarlo en un teatro. La fecha elegida, 6 de agosto de 1824.

Este resumen del argumento borgeano (cuya exposición es infinitamente más complicada) es necesario por la importancia de la fecha elegida para el asesinato que hará posible la metamorfosis del traidor en héroe. Esa fecha coincide con la de la batalla de Junín. Nade sucede en la historia de Irlanda el 6 de agosto de 1824, ni existe ese Fergus Kilpatrick, ni ese Nolan, ni sus traducciones de Shakespeare. Cada uno de esos "datos" ha sido inventado por Borges y hubieran podido ser diferentes excepto en un punto: la fecha, que no tiene para Borges nada de caprichoso ni arbitrario. Por el contrario, el asesinato de Kilpatrick debe suceder el 6 de agosto de 1824 porque ese día también tuvo lugar la batalla de Junín, que fue la más importante en la que participó cualquiera de sus antepasados. Y además abrió el camino a la de Ayacucho, en la que los españoles fueron definitivamente vencidos.

Por eso, la veneración de Borges por su linaje no queda fijada a una escaramuza cualquiera. En este relato decide inscribir la batalla de Junín en una historia irlandesa que también lo es de luchas nacionales por la independencia. América del Sur e Irlanda pertenecen al mismo cronotopo; esto, por lo menos, es lo que puede leerse si se descubre el peso que la fecha de 1824 ejerce sobre Borges, que en un mismo día tiende un puente entre dos luchas nacionales, y, ¿por qué no?, entre dos culturas.

"El tema del traidor y del héroe" salió en la revista Sur en febrero de $1944 .^{23}$ En esa primera versión no tenía el párrafo final, que apareció en la casi inmediata versión de Ficciones. Los bibliotecarios-investigadores Laura Rosato y Germán Álvarez, que encontraron la hojita manuscrita con ese párrafo final dentro del número de Sur donde se publicó el relato, explican:

Borges realizó sobre ese soporte cambios y correcciones manuscritas, antes de su publicación en Ficciones; el más significativo de esos cambios resulta, sin duda, la inserción de un nuevo final - el final definitivo del cuento - ensayado en una esquela

${ }^{23}$ Sur 112 , de febrero de 1944 . Ese mismo año se publicó en el volumen Ficciones. 
suelta, conservada entre las páginas de la revista donde el relato concluye. ${ }^{24}$

Ese párrafo final agregado ilumina el movimiento que hizo Borges sobre su propio argumento. En síntesis: la trama de Nolan (es decir la conversión de un traidor en un héroe) se sostiene en las más fuertes invenciones de la literatura, tal como se encuentran en el teatro de Shakespeare y en las gigantescas puestas en escena populares (como los Festspiele, donde toda una ciudad hace de escenario). El arte produce esa potencia y su juego de espejos no siempre es una refracción imaginaria, sino una oblicua verdad que sostiene lo real. Fergus, el traidor, es parte de la trama de Nolan. No se puede negar que también Borges es parte de la trama de Nolan: aunque la haya inventado, forma parte de ella como garante de un hecho sucedido.

La trama de Nolan tiene como fin construir un héroe. También la de Borges que, en 1944, podía estar bien seguro de que los Húsares de Junín comandados por Isidoro Suárez eran recordados por muy pocos. Al fechar la ejecución/ajusticiamiento de Fergus Kilpatrick en esa fecha del 6 de agosto, nos obliga a recordar la batalla de Junín, sin nombrarla. Para decirlo de modo sencillo: los textos de Borges provocan nuestra desconfianza, como si el lector debiera preguntarse: ¿esta fecha no será una clave? Y, de este modo, disciplinados lectores, escarbamos un dato aparentemente secundario donde se ha enterrado otra verdad, que no es sólo la de la ficción.

Al lector de Borges se aplica lo que, en Fragmentos de un discurso amoroso, Roland Barthes dice del celoso: para él, todo es signo, porque el régimen de sus textos instala la sospecha como principio hermenéutico: ¿hasta dónde puedo creer? No se trata de la "realidad" de los hechos narrados (un tema clásico desde el romanticismo), sino de la secreta polisemia de la narración: en "Tema del traidor y del héroe", una fecha no es simplemente esa fecha, ni localiza solamente un día de la "historia" de Irlanda, sino que también designa otro día en otro continente. Para la "historia" de Irlanda, ese día de agosto de 1824 también es doble: en el

${ }^{24}$ En Jorge Luis Borges, Tema del traidor y del héroe, edición crítico genética y estudio preliminar de Laura Rosato y Germán Álvarez (Buenos Aires: Biblioteca Nacional, 2016), 17. Rosato y Álvarez, que han hecho sustanciales aportes bibliográficos sobre Borges, encontraron entre las colecciones duplicadas de la Biblioteca Nacional un ejemplar del número 112 de Sur. 
mismo acto se castiga la traición y se honra a un héroe falso pero necesario. En la historia americana, la fecha tiene el resplandor de lo único, lo simple y lo definitivo: un antepasado de Borges se convierte en héroe cuando dirige una carga de caballería; sus camaradas lo atestiguan; medio siglo después Mitre lo registra en su Historia; y Borges recibe ese legado como un don inmerecido (dirá probablemente) pero que deberá honrar. Esa fecha de agosto de 1824 es, desde la perspectiva de la historia del mundo, una condensación de realidad e invenciones. Un epígrafe del irlandés W.B. Yeats, ausente de la edición del cuento en Sur pero que encabeza el texto cuando se publica en Ficciones, termina con estos dos versos que Borges cita para indicar el ingobernable y primitivo azar que nos rige:

All men are dancers and their tread

Goes to the barbarous clangour of a gong. ${ }^{25}$

En el "Prólogo" de Ficciones, Borges nombra "el censo heterogéneo de autores que continuamente releo. Entre ellos, Stevenson y Chesterton". Naturalmente, se piensa, al nombrar a Stevenson, en el tema del doble. ${ }^{26}$ Cuando cae asesinado para que su traición permute en heroísmo, Fergus Kilpatrick adquiere una identidad doble: el traidor escondido en el cadáver del mártir por la patria. Así se escribe la historia... La identidad no es sólo inestable, sino que también permuta según el mandato de una causa más alta que jamás debe ser manchada por la traición. Chesterton propone exactamente la misma reescritura de un acto vil en "The Sign of the Broken Sword". En ese relato se recurre a una fallida e inútil carga de caballería del ejército inglés para ocultar el crimen de un solo hombre: gesto descomunal, pero, además, gesto que a Borges lector de Chesterton pudo recordarle otra carga de caballería, la noblemente comandada por su bisabuelo en la batalla de Junín. Permítase la hipótesis de que Borges, cuando escribe un argumento de "traidor y héroe" poniéndole la fecha de esa batalla al instante en que el primero

25 "Todos los hombres bailan y sus pasos / siguen el toque bárbaro de un gong” (trad. B. Sarlo).

${ }^{26}$ Daniel Balderston ha estudiado con erudito detalle e inteligencia la relación entre Borges y Stevenson. Véase: El precursor velado: $R$. L. Stevenson en la obra de Borges (Buenos Aires: Sudamericana, 1982). 
permuta en el segundo, vislumbró dos cargas militares, opuestas en los valores que representaron y en su desenlace, pero unidas metonímicamente como en un sueño.

Así, además de resaltar una fecha, que inscribe a Borges en la historia patria por acción de sus antepasados, "Tema del traidor y del héroe" expone estadios diferentes para la construcción de un mito. En el relato irlandés, hay dos tiempos: uno, contemporáneo a los hechos, cuando un narrador, que forma parte de la escena, los reordena y les atribuye sentidos; así Nolan convierte al traidor Kilpatrick en héroe y establece las condiciones teatrales de su muerte para que parezca un sacrificio aún más glorioso; y otro tiempo, posterior, cuando el bisnieto de Kilpatrick descubre lo que Nolan ha armado para salvar la insurrección ocultando la traición de su antepasado, y, en lugar de escribir la verdad, decide volver a contar esa trama inventada (en The Man Who Shot Liberty Valance el político cuyo personaje representa James Stewart le cuenta a un periodista la verdad sobre un legendario duelo en el Oeste americano y, una vez enterado de lo que había sucedido realmente, el periodista rompe sus notas y afirma: "Cuando la leyenda se convierte en un hecho, hay que seguir publicando la leyenda").

Pero antes de volver al coronel Suárez, algo más sobre una poética de la narración. Por lo menos dos veces, Borges establece que el narrador no debería exponer su trama como si los hechos le parecieran inmediatamente comprensibles. El prólogo a Elogio de la sombra, de 1969, disimula ciertos principios que Borges ha seguido bajo el nombre de "astucias", para no correr el riesgo de engrandecerlos como elecciones estéticas, ya que se sabe que cualquier afirmación sobre su obra le parecía hiperbólica e implacablemente destinada a la atenuación irónica. Entre esas "astucias", Borges anota la siguiente: "Narrar los hechos (esto lo aprendí en Kipling y en las sagas de Islandia) como si no los entendiera del todo". Por supuesto, la última "astucia" que menciona Borges es que ninguna de las mencionadas antes es una obligación y deja al lector futuro con la responsabilidad estética de juzgar si la "astucia" ha sido o no utilizada o si el tiempo se encargó de abolirla (son las palabras de Borges). También en Elogio de la sombra, Borges recompone en "Pedro Salvadores" el recuerdo de su abuelo materno, Isidoro Acevedo, sobre un hombre que permaneció diez años escondido en un sótano hasta la caída de Rosas. Acevedo lo conoció, ablandado, pálido, 
mudo y miserable, después de Caseros, en febrero de 1852. Hasta allí el recuerdo, pero Borges agrega una indecisión fundamental con la que, a su vez, concluye el relato: "Como todas las cosas, el destino de Pedro Salvadores nos parece un símbolo de algo que estamos a punto de comprender". Pero es evidente que no comprendemos. ${ }^{27}$

\section{GLORIA Y OLVIDO}

En "Kafka y sus precursores" Borges establece un principio de organización de la historia literaria. Diversos textos pueden permanecer sin ninguna conexión entre sí, hasta que uno nuevo los convierta en algo diferente a lo que fueron antes de la aparición de ese que los anteriores no habían previsto: "Cada escritor crea a sus precursores". ${ }^{28}$

También Borges crea a sus precursores. No me refiero, en este caso, a sus precursores literarios, sino a la versión de la historia en la que se colocan sus antepasados. Lo hace hasta en textos últimos, definitivamente finales. A Isidoro Suárez le dedica tres poemas, fechados en 1928, 1953 (El otro, el mismo) y 1976 (La moneda de hierro). Se conoce una historia de los Grandes Jefes, digamos la historia clásica de Belgrano y San Martín que escribió Mitre. Borges la duplica, en paralelo, con una historia familiar de soldados. Hay poemas a estos soldados en obras de la madurez, pero importa más encontrarlos en los primeros libros, donde Borges se constituye como escritor y traza la escena de su mitología criolla enlazada con la historia personal de un heredero. Importa encontrarlos en esa proximidad inicial que, en el caso de Borges, se mantiene como una especie de bajo continuo hasta el final. ${ }^{29}$

Por supuesto, Isidoro Suárez es el antepasado más notable de este linaje. Pero no es quien suscita el poema más íntimo de la serie de "precursores", sino el padre de Leonor, su madre. En ese poema, Isidoro Acevedo, afiebrado y cerca de la muerte, reúne una milicia imaginaria, sombras que habían guerreado con él en Cepeda y Pavón, para pelear una batalla final. El poema le da una fecha a ese sueño: 1905, cuando Borges era un niño. Veinte años después imagina y escribe el sueño de

${ }^{27}$ O.C., 975 y 995 , respectivamente.

${ }^{28}$ O.C., 710-712.

${ }^{29}$ A esta continuidad me he referido más extensamente en Borges, un escritor en las orillas (Buenos Aires: Siglo XXI, 2015). 
su abuelo. "Isidoro Acevedo" comienza con la admisión de un desconocimiento: "Es verdad que lo ignoro todo sobre él / salvo los nombres de lugar y las fechas...". ¿Cómo así? Porque Borges se atreve a más: sólo evocará una sucinta historia de Isidoro Acevedo porque el poema contará no su vida exterior, sino su último sueño, el que precedió a la muerte: "Soñó con dos ejércitos"; "Hizo leva de pampa"; "Entró a saco en sus días para esa visionaria patriada"; "Juntó a un ejército de sombras porteñas"... ${ }^{30}$ Un cuarto de siglo después Borges volvió a soñar el sueño de su abuelo materno. Sella de este modo una herencia: no sólo pertenece a un linaje, sino que además lo acepta como identificación. Esta marca perdura.

El abuelo paterno recibe la ofrenda de "Al coronel Francisco Borges", poema publicado en Luna de enfrente, de 1925. Y mucho después está una "Alusión a la muerte del coronel Francisco Borges". ${ }^{31}$ El primer poema es, sin duda, el más denso en términos literarios y afectivos, al evocar una muerte gloriosamente insensata, honorable y leal en la batalla de La Verde, donde sucumbió la insurrección encabezada por Mitre contra la elección de Avellaneda como presidente:

El día 28 de noviembre de 1874 ,

para que te viera la muerte,

montabas un caballo plateado

$\mathrm{y}$ te envolviste en un poncho blanco. ${ }^{32}$

El héroe, en verdad, no evita la muerte, sino que la busca. El coronel Borges protagoniza una epopeya fantasmal, movido por una lealtad a su palabra que también es, en el siglo XX, parte de un recuerdo.

Estos abuelos están desde el principio de la obra poética. Juntos en "Dulcia linquimus arva": "Uno peleó contra los godos / otro en el Paraguay cansó su espada". ${ }^{33}$ Isidoro Suárez y Francisco Borges son maestros de un saber que Borges no posee: baqueanos de un espacio que el poeta urbano sólo puede imaginar. Las palabras elegidas condensan escenarios, situaciones y paisajes en un nudo lexical criollo:

\footnotetext{
${ }^{30}$ Cuaderno San Martín, en Poemas, 128-30.

${ }^{31}$ O.C., 828.

32 Poemas, 94.

33 "Dulcia linquimus arva", Luna de enfrente, en Poemas, 104.
} 
Descifraron lejanas polvaredas

en carretas o en caballadas

y los alegró el resplandor

con que aviva el sereno la luz de la espadaña.

(...)

Resplandecientes y altos eran sus días

hechos de cielo y llano.

Sabiduría de tierra adentro la suya,

de la lazada que es comida

y de la estrella que es vereda

y de la guitarra encendida. ${ }^{34}$

Un último texto vuelve a reunir a estos abuelos en "La Recoleta", el cementerio sobre el que Borges escribe uno de los primeros poemas de su primer libro. En aquel remoto poema, el joven Borges ya tiene la seguridad de que él también tendrá allí su tumba, como la tendrán sus padres. Construido sobre anáforas que introducen denegaciones ("Aquí no está... Aquí no está...), el poema señala la ausencia de los restos físicos de cada uno de los muertos, que el tiempo ha reducido a polvo y cenizas, pero al hacerlo conserva sus figuras en el recuerdo literario. Sobre todo, une los nombres de los dos antepasados que antes había evocado:

Aquí no está Isidoro Suárez, que comandó una carga de húsares en la batalla de Junín, que apenas fue una escaramuza y que cambió la historia de América.

Aquí no está Félix Olavarría, que compartió con él las campañas, la conspiración, las leguas, la alta nieve, los riesgos, la amistad y el destierro. Aquí está el polvo de su polvo.

Aquí no está mi abuelo, que se hizo matar después de la capitulación de Mitre en La Verde. ${ }^{35}$

La muerte ordena a estos hombres. Aunque para Borges ya no fuera su ley la del coraje, sus antepasados se convirtieron en precursores. Dejaron de ser sólo una línea genealógica y formaron una línea históri-

34 "Luna de enfrente", en Poemas, 104-5.

${ }^{35}$ Atlas (Buenos Aires, 1984), 54. 
ca que le dio sentido. Antes de ser ordenados por Borges, eran militares valientes y seguramente leales a sus jefes, pero sólo eso: destinados a una nota erudita. Borges les restituye una vibración en su propio presente. Olavarría, a quien Borges menciona, participa de este linaje porque, como se vio, fue quien relató a Mitre los pormenores de la batalla de Junín, en la que participó junto a su amigo Suárez. Siguiendo este relato, que es al mismo tiempo parte de la historia y del patrimonio de su familia, Borges afirma que aquella famosa carga de caballería "fue una batalla de lanzas en la que no retumbó un solo tiro". ${ }^{36}$

Al nombrar a sus antepasados, Borges evita que sus apellidos caigan en la definitiva indiferencia de designar una calle porteña. ${ }^{37}$ Recopila la memoria familiar y restaura el acero de la espada de aquellos que corren todos los peligros del olvido. La herencia de Borges se consolida en su propia construcción de precursores. Las sombras casi borradas de oficiales de la independencia y de las guerras civiles, de las campañas en Paraguay o contra los indios, de repente, comienzan a brillar más que si estuvieran escritas en las páginas liminares de una historia patriótica, esas páginas reservadas a los Héroes.

La literatura prueba, una vez más, ser aere perennius, más duradera que el bronce. Ante el busto del coronel Suárez en la ciudad bonaerense que lleva su nombre, Borges evoca una melancólica desolación pampeana. La estatua de Suárez le muestra una "faz de metal y de melancolía" ${ }^{38}$. Vale la pena detenerse porque surge reveladora la hipálage, la figura retórica que Borges emplea para pasar de lo objetivo a lo subjetivo. Ciertamente, el rostro de Suárez es de metal. Pero la unión de esa materia, usada para representar a Suárez, con la melancolía, lleva el verso de lo objetivo de una cosa pública (la estatua de su antepasado) al sentimiento borgeano de una pérdida. El poeta es el melancólico, no el

36 "Página para recordar al coronel Suárez, vencedor en Junín”, El otro, el mismo, en $O . C$., 872. Escribe Mitre: "Fue un combate al arma blanca: no se disparó un solo tiro. Quedaron en el campo 250 realistas muertos a sable y lanza" (Historia de San Martín, 728).

${ }^{37}$ En "La noche cíclica", Borges escribe: "De mi sangre: Laprida, Cabrera, Soler, Suárez... / Nombres en que retumban (ya secretas) las dianas, / las repúblicas, los caballos y las mañanas, / las felices victorias, las muertes militares" (Poemas, 165).

38 "Coronel Suárez", La moneda de hierro, primera edición 1976. Se cita de Obra poética (Buenos Aires: Emecé, 1989), 443. 
coronel Suárez. Es el poeta el que se entrega al deber filial y patriótico de rescatar los nombres secundarios y reordenarlos en esa secuencia que termina en él y ha tomado definitivamente un nuevo sentido para nosotros. ${ }^{39}$

Borges no altera los acontecimientos, porque no encuentra en ellos la mancha que encontró Ryan en la historia del traidor devenido héroe. $\mathrm{Su}$ intervención es simplemente un acercamiento a esos soldados que, ya en el siglo XX, estaban entrando en el olvido de las estatuas por cuyo sentido ya nadie se pregunta. Acerca el foco a la batalla y dispone los personajes en una perspectiva a la vez histórica y subjetiva. Sabe, de todas formas, lo que cree haber escuchado con la voz del coronel Suárez, en el final de la "Página" que escribe para recordarlo: "Qué importa mi batalla de Junín si es una gloriosa memoria, una fecha que se aprende para un examen o un lugar en el atlas". ${ }^{40}$ Cuarenta años antes lo había anticipado en "Inscripción sepulcral": "Hoy es orilla de tanta gloria el olvido". Pero décadas después tachó este verso y lo reemplazo por "Ahora es un poco de ceniza y de gloria". ${ }^{41}$ Las citas entrelazan gloria y olvido.

Sin embargo, la "Página para recordar al coronel Suárez" no termina aquí. Inesperado, el presente irrumpe dado que es imposible renunciar a lo que el peronismo, en 1953, significaba para Borges: "Junín son dos civiles que en una esquina maldicen a un tirano, / o un hombre oscuro que se muere en la cárcel". Suárez, de pronto, vale no sólo como precursor borgeano, sino como precursor de otros sobre quienes Borges deposita la esperanza de que luchen contra aquel gobierno y aquel hombre que, en 1953, lo agobian como una tiranía. Su antiperonismo es transhistórico. Corrobora esa perspectiva el final del prólogo pesimista e irónico a La moneda de hierro, publicado en 1976:

No en vano fui engendrado en 1899. Mis hábitos regresan a aquel siglo y al anterior y he procurado no olvidar mis remotas y ya desdibujadas humanidades (...). Me sé del todo indigno de opinar en materia política, pero tal vez me sea perdonado añadir que descreo de la democracia, ese curioso abuso de la estadística.

${ }^{39}$ Ibídem.

40 "Página para recordar", 872.

${ }^{41}$ La primera versión está en la edición de Fervor de Buenos Aires incluida en Poemas. La segunda, en O.C. 


\section{VINDICACIÓN Y CRÍTICA DE LA RAZÓN}

Se dirá: Borges trabajó con máxima intensidad textos cuya trama se resuelve no sólo en el pasado real o imaginario, no sólo en los espejos y laberintos fantásticos, sino también en el conflicto con el desorden de una razón que antes supo disponer y mandar. Borges conoce el pavoroso abismo donde se hunde la razón y el no menos terrible donde se impone su ley de hierro sobre el universo. Conoce el amor por la geometría y la crítica a sus disciplinadas figuras. Son tan ciertas una proposición de esta disyuntiva como la otra. En la figura del doble, estas dimensiones en conflicto conviven y se enfrentan, como aquellos teólogos que dedicaron sus vidas a polemizar y acusarse de herejía para descubrir que, frente a Dios, "formaban una sola persona". Ese final es temible y deletéreo porque pone en cuestión la identidad. Por eso, como se vio, Borges acepta su linaje como herencia y, por eso, está en condiciones de reconocer en las historias inversas de una cautiva pampeana y del bárbaro Droctulft que "el anverso y el reverso de esta moneda son, para Dios, iguales". ${ }^{4}$

La obra de Borges abre un continente de impossibilia perfectamente razonados y de extremismos que la razón se ve obligada a aceptar porque se los expone con la gélida geometría de un cuento como "La muerte y la brújula", donde la razón de quien investiga y los procedimientos de quien comete un crimen están dispuestos en el espacio con el orden de una demostración. Todos los argumentos de Borges son complicados. No son inverosímiles, ni exigen ser aceptados simplemente porque se los enuncia con magistral destreza. Son sencillamente complicados, para usar el oxímoron que mejor los describe. Podría decirse que se atienen al mandamiento narrativo que Bertolt Brecht enuncia en Baal: "Las historias que se entienden del todo están mal contadas".

Un hombre en el siglo XX escribe el Quijote. ¿Hay algo más que la locura?; ¿esa locura es una ironía o una alegoría del hecho literario?; ¿en verdad, se trata del acto literario o de una obsesión que puede tener como objeto sólo un texto excepcional? Por supuesto, la crítica de las últimas décadas ha encontrado en ese relato todas las insinuaciones de su propio sistema teórico, pero frente a esas claves que se creyó encon-

42 "Los teólogos", El Aleph, en O.C., 556. "Historia del guerrero y la cautiva", en O.C., 560 . 
trar cabe nuevamente la pregunta sobre los cuentos de Borges como artefactos especialmente preparados para la teoría crítica. La visión clasificatoria y ordenadora (como en "La lotería en Babilonia") coexiste con jerarquías espaciales infinitas $y$, por lo tanto, inaccesibles en su totalidad a la experiencia (como en "La biblioteca de Babel"); los lenguajes artificiales y las enciclopedias procuran remediar el caos de los sentidos y de las etimologías, el aleph de un mundo de significaciones que siempre vencerá al método que pretenda organizarlo. Borges instala tantos órdenes improbables porque también en esta dimensión siente nostalgia (que sabe destinada al fracaso y, en ocasiones, al patetismo escéptico) por un orden primordial desconocido y perdido para siempre: "Cabe sospechar que no hay universo en el sentido orgánico, unificador, que tiene esa ambiciosa palabra. Si lo hay, falta conjeturar su propósito; falta conjeturar las palabras, las definiciones, las etimologías, las sinonimias, del secreto diccionario de Dios". ${ }^{43}$

En esa batalla interminable por el sentido quizá también pelearon los héroes familiares. Con la modernidad, esos hombres del linaje heredado por Borges entraron en una irremisible dimensión arcaica. Son el pasado; están desvaídos y desarmados, como figuras que llegan desde una lejana derrota. Foucault pudo reír con la borgeana enciclopedia china que, al desclasificar o proponer clasificaciones extravagantes, erosiona la lógica de las jerarquías y los poderes. También los sueños desclasifican: "Si un hombre atravesara el paraíso en un sueño, y le dieran una flor como prueba de que había estado allí, y si al despertar encontrara esa flor en su mano... ¿entonces, qué?" 44 Lo que entonces sucedería lo supo Borges: los objetos y los seres trashumantes están heridos en su sustancia y debilitados en su identidad. Otra pérdida de la razón moderna. Otra nostalgia. Ya nadie podrá guerrear con la firmeza y el estólido valor de Isidoro Suárez, ni morir la muerte honrosa del coronel Borges. Los espacios vacilan y, en ellos, tiemblan los valores que pertenecieron a un ethos clásico y a la moral de los discretos héroes civiles de las guerras suramericanas, cuyo legado Borges recibió, pero del que no fue sólo un heredero, sino quien lo escribió con el rumor de hexámetros atenuados por el ritmo del octosílabo criollo.

43 "El idioma analítico de John Wilkins", Otras inquisiciones, en O.C., 708.

44 "El sueño de Coleridge", Otras inquisiciones, en O.C., 642-45. 


\section{BIBLIOGRAFÍA}

Balderston, Daniel. "Digamos Irlanda, digamos 1824". En Innumerables relaciones. Cómo leer con Borges. Santa Fe: Universidad Nacional del Litoral, 2010.

- El precursor velado: R. L. Stevenson en la obra de Borges. Buenos Aires: Sudamericana, 1982.

Borges, Jorge Luis. Atlas. Buenos Aires, 1984.

—. Inquisiciones. Buenos Aires: Seix-Barral, 1993.

—. Obras completas. Buenos Aires: Emecé, 1974.

- Obra poética. Buenos Aires: Emecé, 1989.

—. Poemas. 1922-1943. Buenos Aires: Losada, 1943.

—_. El tamaño de mi esperanza. Buenos Aires: Seix-Barral, 1993.

—. "El tema del traidor y del héroe". Sur 112 (1944).

- Tema del traidor y del héroe. Edición crítico genética y estudio preliminar de Laura Rosato y Germán Álvarez. Buenos Aires: Biblioteca Nacional, 2016.

Botana, Natalio. "La lucha por la capital". En Buenos Aires; historia de cuatro siglos, editado por José Luis Romero \& Luis Alberto Romero, vol. 1. Buenos Aires: Editorial Abril, 1983.

Fraga, Rosendo. Borges y el culto de los mayores. Prólogo de María Kodama. Buenos Aires: Fundación Internacional Jorge Luis Borges, 2001.

Gamerro, Carlos. Borges y los clásicos. Buenos Aires: Eterna Cadencia, 2016.

Güiraldes, Ricardo. Don Segundo Sombra. 1926.

Hernández, José. El gaucho Martín Fierro. 1872.

Mitre, Bartolomé. Historia de San Martín y de la emancipación sudamericana, tomo 3. Buenos Aires: Imprenta de "La Nación", 1888.

Sarlo, Beatriz. Borges, un escritor en las orillas. Buenos Aires: Siglo XXI, 2015.

—. La imaginación técnica. Sueños modernos de la cultura argentina. Buenos Aires: Nueva Visión, 1994.

Spinoza, Baruj de. Ética, vol. III. Madrid: Alianza, 2009. EP 